\section{NORMAL VALUES FOR ARTERIAL STIFFNESS IN A LARGE COHORT OF HEALTHY CHILDREN AND ADOLESCENTS}

\author{
D. Kracht ${ }^{1}$, A. Doyon ${ }^{2}$, C. Jacobi ${ }^{1}$, F. Schaefer ${ }^{2}$, \\ B. Schmidt ${ }^{3}$, S. Sorrentino ${ }^{3}$, E. Wühl ${ }^{2}$, A. Melk ${ }^{1}$
}

${ }^{1}$ Paediatric Nephrology, Hannover Medical School, Hannover, ${ }^{2}$ Paediatric Nephrology, University

Hospital Heidelberg, Heidelberg, ${ }^{3}$ Nephrology,

Hannover Medical School, Hannover, Germany

Background and aims: Aortic pulse wave velocity (aPWV), an early indicator of arterial stiffness, predicts cardiovascular mortality risk in adults. Since children with kidney disease have a high risk for cardiovascular mortality later in life, early detection of advanced arterial stiffening would be important. In childhood, aPWV has not been investigated in larger cohorts. The aim of this study was to provide normal values and to prove the suspected increase with age.

Methods: Pulse waves were captured by oscillometry simultaneously on the right carotid and femoral artery (Vicorder) in 405 healthy school children aged 6 to 18 years. In addition, we measured intima-media thickness (IMT) and elasticity on both carotid arteries by B- and M-Mode ultrasound.

Results: aPWV significantly increased with age. 6-8 year olds $(n=97): 4.2 \pm 0.4 \mathrm{~m} / \mathrm{s} ; 9-11$ year olds $(n=135): 4.5 \pm 0.4 \mathrm{~m} / \mathrm{s} ; 12-14$ year olds $(n=97)$ : $4.9 \pm 0.5 \mathrm{~m} / \mathrm{s} ; 15-18$ year olds $(n=76): 5.2 \pm 0.5 \mathrm{~m} / \mathrm{s}$ $(p<0.0001)$. aPWV significantly correlated with age $(r=0.63, p<0.0001)$. Further significant correlations: weight, height, mean systolic and diastolic blood pressure. aPWV did not correlate with IMT, but significantly with elasticity parameters: incremental elastic modulus $(r=0.43, p<0.0001)$, distensibility coefficient $(r=-0.42, \quad p<0.0001)$. Independent predictors for aPWV in multiple regression analysis were: age, gender, diastolic blood pressure and elasticity parameters.

Conclusions: This study defines normal values for aPWV in children and adolescents using a new non-invasive oscillometric method. Even in healthy young individuals we detected correlations to cardiovascular risk factors. Interestingly, a connection of aPWV to functional parameters of arterial elasticity was observed.

\section{THE EFFECT OF ENTERAL SUPPLEMENTATION OF NEUTRAL AND ACIDIC OLIGOSACCHARIDES ON THE RESPONSE TO VACCINATIONS IN PRETERM INFANTS}
J.P. van den Berg ${ }^{1}$, E.A.M. Westerbeek ${ }^{1}$, G.A.M. Berbers ${ }^{2}$, F.R.M. van der $\mathrm{Klis}^{2}$, H.N. Lafeber ${ }^{1}$, R.M. van Elburg ${ }^{1}$
${ }^{1}$ VU University Medical Center, Amsterdam, ${ }^{2}$ National Institute for Public Health and the Environment, Bilthoven, The Netherlands

Background and aims: We aimed to determine the effects of enteral supplementation of a prebiotic mixture of neutral and acidic oligosaccharides ( ${ }_{S C}$ GOS/LCOS/AOS), who are supposed to improve the development of the immune system and therefore improve the immune response to DTaPHib vaccinations in preterm infants.

Methods: In a RCT, preterm infants with a gestational age $<32$ weeks and/or birth weight $<1500 \mathrm{~g}$ received enteral supplementation of ${ }_{S C}$ GOS/ $L C$ FOS/AOS or a placebo (maltodextrin) between days 3-30 of life. Serum samples were taken at 5 and 12 months of age, after the $3^{\text {th }}$ and $4^{\text {th }}$ vaccination respectively. Samples were analyzed by multiplex immune assay (MIA, Luminex).

Results: In total, 89 preterm infants at 5 months and 85 infants at 12 months were included. Baseline patient and nutritional characteristics were not different between both groups. Results are shown in table 1. No significant differences were shown (all $p>0.05)$.

Table 1. Vaccination response of preterm infant at 5 and 12 months.

\begin{tabular}{|c|c|c|c|c|c|c|}
\hline & $\begin{array}{l}\text { Ptx } \\
\text { (EU/ } \\
\mathrm{ml})\end{array}$ & $\begin{array}{l}\text { FHA } \\
\text { (EU/ } \\
\mathrm{ml})\end{array}$ & $\begin{array}{l}\text { Prn } \\
(\mathrm{EU} / \\
\mathrm{ml})\end{array}$ & $\begin{array}{l}\text { Dtx } \\
\text { (IU/ } \\
\mathrm{ml})\end{array}$ & $\begin{array}{l}\text { Ttx } \\
\text { (IU/ } \\
\mathrm{ml})\end{array}$ & $\begin{array}{l}\mathrm{Hib} \\
(\mu \mathrm{g} / \\
\mathrm{ml})\end{array}$ \\
\hline & $\begin{array}{l}512 \\
\mathrm{~m}\end{array}$ & $\begin{array}{l}512 \\
\mathrm{~m}\end{array}$ & $\begin{array}{l}512 \\
\mathrm{~m}\end{array}$ & $\begin{array}{l}512 \\
\mathrm{~m}\end{array}$ & $\begin{array}{l}512 \\
\mathrm{~m}\end{array}$ & $\begin{array}{l}512 \\
\mathrm{~m} \\
\end{array}$ \\
\hline $\begin{array}{l}\text { sc GOS/ } \\
\text { LCFOS/ } \\
\text { AOS }\end{array}$ & 3552 & $\begin{array}{l}71 \\
121\end{array}$ & $\begin{array}{l}72 \\
118\end{array}$ & $\begin{array}{l}0.36 \\
0.88\end{array}$ & $\begin{array}{l}0.72 \\
1.63\end{array}$ & $\begin{array}{l}0.37 \\
2.67\end{array}$ \\
\hline Placebo & 4466 & $\begin{array}{l}96 \\
119\end{array}$ & $\begin{array}{l}80 \\
106\end{array}$ & $\begin{array}{l}0.57 \\
1.14\end{array}$ & $\begin{array}{l}0.99 \\
1.86\end{array}$ & $\begin{array}{l}0.63 \\
2.87\end{array}$ \\
\hline
\end{tabular}

[Table 1]

Conclusions : Enteral supplementation with the prebiotic mixture of neutral and acidic 
oligosaccharides did not influence the immune response on vaccinations against DTaP-Hib in preterm infants.

18

\section{PRETERM INFANTS DO NOT UPREGULATE GSH SYNTHESIS DURING SEPSIS}

D. Rook ${ }^{1}$, H. Schierbeek ${ }^{1}$, J. de Groot ${ }^{1}$, M. Longini' ${ }^{2}$, G. Buonocore ${ }^{2}$, J.B. van Goudoever ${ }^{1}$

${ }^{1}$ Pediatrics, Division of Neonatology, Erasmus MC - Sophia Childrens Hospital, Rotterdam,

The Netherlands, ${ }^{2}$ Pediatrics, Obstetrics and Reproductive Medicine, University of Siena, Siena, Italy

Background and aims: Preterm infants with sepsis have poorer long term outcome than preterm controls. Free radical production is increased during sepsis and the severity of oxidative stress is related to outcome. Preterm infants have reduced antioxidant defenses in the direct postnatal phase. We hypothesized that preterm infants are unable to up regulate the synthesis rate of the major intracellular antioxidant, glutathione (GSH), during sepsis, which could provide a mechanism through which sepsis might have a detrimental effect. The aim of this study was to quantify GSH synthesis rates in erythrocytes of preterm infants with sepsis and control subjects.

Methods: Preterm infants (birth weight < 1500 g) who were diagnosed with nosocomial sepsis (according to CDC criteria) and matched controls were included. [U-13 C]glycine, a precursor for $\mathrm{GSH}$ synthesis, was administered within 24 hours after onset of symptoms to determine fractional synthesis rate (FSR). Glycine enrichment in GSH was determined using liquid chromatography coupled to isotope ratio mass spectrometry (LC-IRMS). Absolute synthesis rate was calculated from the FSR and GSH concentration. In plasma, oxidative stress markers were determined.

Results: Gestational age $\left(27^{1} /{ }_{7} \pm 21 / 7\right.$ weeks), birth weight $(872 \pm 220 \mathrm{~g})$, age at study ( $9 \pm 5$ days) and weight at study $(909 \pm 246 \mathrm{~g})$ were not significantly different between groups ( $n=7$ each). GSH synthesis rates and concentration were not statistically different (figure).

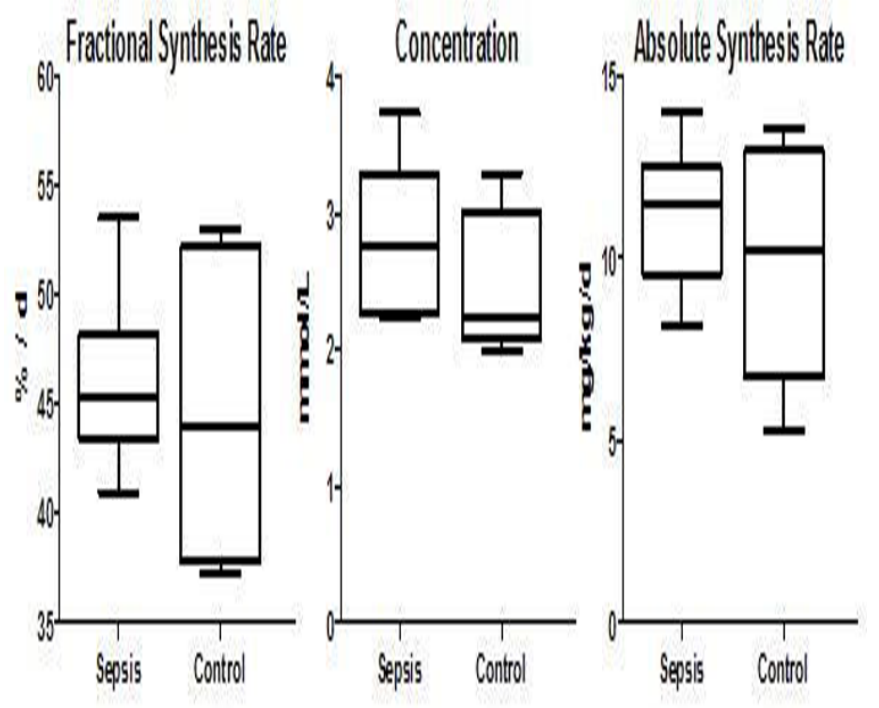

[GSH kinetics (presented as median and minmax)]

Conclusion: Preterm infants did not upregulate the GSH synthesis in response to sepsis, but GSH concentrations were not lowered by sepsis either.

19

A-LACTALBUMIN AND CASEINGLYCOMACROPEPTIDE HAVE NO EFFECT ON IRON ABSORPTION FROM LOW-IRON FORMULA IN HEALTHY TERM INFANTS
E.A. Szymlek-Gay ${ }^{1}$, O. Hernell ${ }^{1}$, S.A. Abrams², B. Lönnerdal ${ }^{3}$, G. Graverholt ${ }^{4}$, M. Domellöf ${ }^{1}$
${ }^{1}$ Department of Clinical Sciences, Pediatrics, Umeå University, Umeå, Sweden, ${ }^{2}$ US Department of Agriculture/Agricultural Research Service Children's Nutrition Research Center, Department of Pediatrics, Baylor College of Medicine, Houston, TX, ${ }^{3}$ Department of Nutrition, University of California, Davis, CA, USA, ${ }^{4}$ Arla Foods Ingredients, Aarhus, Denmark

Background and aims: Iron absorption from infant formula is low. $\alpha$-Lactalbumin and caseinglycomacropeptide are thought to enhance mineral absorption. We evaluated the effects of $\alpha$-lactalbumin and casein-glycomacropeptide on iron absorption from low-iron infant formula in healthy term noniron-deficient infants.

Methods: In a double-blind randomized controlled trial, 32 infants were assigned to receive one of three low-iron ( $4 \mathrm{mg}$ iron/L) formulas from 6 weeks to 